\title{
Associated Factors and Outcomes of Dysmenorrhea Among Female Nursing Students at King Abdulaziz University
}

\author{
Fawziya Alghamdi, Ahlam Al-Zahrani*, Hawa Alabdulaziz \\ Maternity and Child Nursing Department, Faculty of Nursing, King Abdulaziz University, Jeddah, Kingdom of Saudi Arabia
}

\section{Email address:}

aealzahrani@kau.edu.sa (A. Al-Zahrani)

${ }^{*}$ Corresponding author

\section{To cite this article:}

Fawziya Alghamdi, Ahlam Al-Zahrani, Hawa Alabdulaziz. Associated Factors and Outcomes of Dysmenorrhea Among Female Nursing Students at King Abdulaziz University. American Journal of Nursing Science. Vol. 8, No. 1, 2019, pp. 18-25.

doi: 10.11648/j.ajns.20190801.13

Received: December 18, 2018; Accepted: January 10, 2019; Published: January 31, 2019

\begin{abstract}
Background: Dysmenorrhea is a common menstrual complaint around the world, and it negatively affects women's quality of life. The present study aims to identify the associated factors of dysmenorrhea and outcomes among female nursing students at King Abdulaziz University (KAU). Methods: A cross-sectional study was conducted on 194 dysmenorrhea undergraduate female nursing students from the Faculty of Nursing at KAU. Self-administered questionnaires were used to obtain relevant data, which was analysed using SPSS version 24. Result: The study found that a heavy menstrual flow increases the severity of dysmenorrhea, while exercising three times per week decreases the severity of dysmenorrhea. A significant association was found between the severity of dysmenorrhea and feelings of inferiority sleep disturbances, depressed mood, decreased social activities and conflicts with others. Conclusion: Dysmenorrhea is a common health concern among young women with negative outcomes, and awareness of the factors associated with dysmenorrhea intensity can help health care professionals provide proper management to relieve or reduce its adverse effects. Additional studies on the factors associated with dysmenorrhea intensity in different populations are also necessary.
\end{abstract}

Keywords: Dysmenorrhea, Associated Factors, Outcome, Nursing Students

\section{Introduction}

Dysmenorrhea is one of the most frequent gynaecologic disorders, affecting more than half of menstruating females [1]. It is defined as a cramping pain in the lower abdomen, and it may be associated with headaches, dizziness, diarrhea, nausea, vomiting, backaches and leg pain [2]. Dysmenorrhea can have significant negative impacts on the lives of reproductive women, including reduced quality of life, mental health issues and reduced productivity for at least a portion of each month [3].

Ranges of associated factors for dysmenorrhea have been identified in the literature of $\mathrm{Ju}$ et al. and show inconclusive results [4]. In general, dysmenorrhea has associations with age, [5] coffee consumption, [6] body mass index (BMI), [7] skipping breakfast, [8] exercise habits, [9] sleep duration, [7] education specialty, [8] physical activity, a young age at menarche, [10] family history of dysmenorrhea, $[11,10,6]$ depression and stress [9]. Despite the identification of this range of associated factors for dysmenorrhea, the research studies shows conflicting results [4]. Additional studies are required to further understand the factors associated with dysmenorrhea, which may help health care professionals to establish proper management plans to reduce the adverse effects of dysmenorrhea. This study aims to identify the associated factors of dysmenorrhea and its outcomes among female nursing students at King Abdulaziz University (KAU).

\section{Methods}

This cross-sectional study was conducted within the Faculty of Nursing at KAU in the Kingdom of Saudi Arabia (KSA) among 194 dysmenorrheal bachelor female nursing students, who were purposefully selected. Prior to the study, 
approval was obtained from the Research Ethics Committee of the Faculty of Nursing at KAU. Participants were given information about the purpose and protocol of the study, and informed consent was obtained prior to data collection. A self-administered questionnaire collected data on the sociodemographics, personal habits/lifestyle, menstrual history and obstetrical history, as well as the impact of dysmenorrhea on the physical and psychological wellbeing of the study participants. The questionnaire included the verbal multidimensional scoring system (VMS) to assess the severity of dysmenorrhea. Data were analysed using SPSS Statistics version 24. The normal distribution of the data was tested, and Chi-square and Spearman tests were used to test the correlations between variables.

\section{Results}

A total of 194 nursing students were included in the present study. As illustrated in Figure 1, more than half of the participants $(\mathrm{n}=117,60.4 \%)$ suffered from moderate dysmenorrhea during menstruation and $21.6 \%(n=42)$ had severe dysmenorrhea.

The majority of the participants $(n=189,97.4 \%)$ were between 19 and 24 years-old, and a similar percentage $(97.9 \%)$ were single and lived with family $(n=183,94.8 \%)$. Two thirds of the participants $(n=121,64.7 \%)$ were from the western region of the Kingdom, and had a normal BMI. Participants were from varied academic levels, from second, third, and fourth year, with the following percentages respectively: $(n=64,33.0 \% ; n=79,40.7 \%$; and $n=51$, $26.3 \%)$. Less than half of the participants $(n=74,39.2 \%)$ had a monthly income of less than 5000 SR. Regarding the education level of the participants' parents, high school was the highest percentage for both mothers and fathers: $(n=84$, $43.3 \%)$ and $(n=74,38.1 \%)$ respectively. Around three quarters of the participants had low haemoglobin $>12.1 \mathrm{~g} / \mathrm{dl}$ $(n=141,72.7 \%)$.

According to the Chi-Square test, there was no statistical significance between the severity of dysmenorrhea and the socio-demographic data among the participants. Table 1. illustrates the distribution of the severity of dysmenorrhea with participants' socio-demographic data.

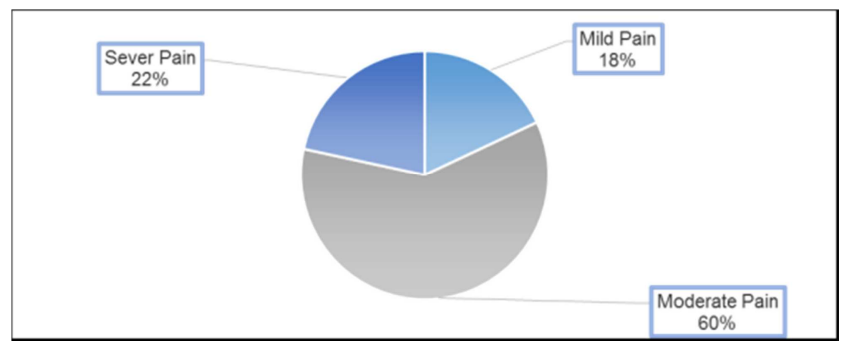

Figure 1. Severity of Dysmenorrhea.

Table 1. Distribution of severity of dysmenorrhea with participants' socio-demographic data.

\begin{tabular}{|c|c|c|c|c|c|c|}
\hline \multirow{2}{*}{\multicolumn{2}{|c|}{ Socio-Demographic }} & \multicolumn{3}{|c|}{ Severity of Dysmenorrhea } & \multirow{2}{*}{$\mathrm{CC}$} & \multirow{2}{*}{$\mathbf{P}$ - Value } \\
\hline & & Mild n (\%) & Moderate n (\%) & Severe n (\%) & & \\
\hline \multirow{2}{*}{ Marital Status } & Single & $34(17.5)$ & $115(59.3)$ & $41(21.1)$ & \multirow{2}{*}{0.032} & \multirow{2}{*}{0.904} \\
\hline & Married & $1(0.5)$ & $2(1.0)$ & $1(0.5)$ & & \\
\hline \multirow{3}{*}{ Residency } & With family & $35(18.0)$ & $111(57.2)$ & $37(19.0)$ & \multirow{3}{*}{0.144} & \multirow{3}{*}{0.395} \\
\hline & Dormitory & - & $4(2.1)$ & $2(1.0)$ & & \\
\hline & Alone & - & $2(1.0)$ & $2(1.0)$ & & \\
\hline \multirow{3}{*}{ Academic Year } & Second & $9(4.6)$ & $30(15.5)$ & $12(6.1)$ & \multirow{3}{*}{0.054} & \multirow{3}{*}{0.966} \\
\hline & Third & $15(7.7)$ & $49(25.3)$ & $15(7.7)$ & & \\
\hline & Fourth & $11(5.7)$ & $38(19.6)$ & $15(7.7)$ & & \\
\hline \multirow{3}{*}{ Income } & Less than $5000 \mathrm{SR}$ & $5(2.6)$ & $42(21.6)$ & $17(8.8)$ & \multirow{3}{*}{0.073} & \multirow{3}{*}{0.908} \\
\hline & $5000-10000 \mathrm{SR}$ & $7(3.6)$ & $29(19.5)$ & $10(5.1)$ & & \\
\hline & More than 10000 SR & $11(5.7)$ & $44(22.7)$ & $14(7.2)$ & & \\
\hline \multirow{5}{*}{ Origin Region } & North & $1(0.5)$ & $6(3.1)$ & $2(1.0)$ & \multirow{5}{*}{0.178} & \multirow{5}{*}{0.630} \\
\hline & South & $6(3.1)$ & $14(7.2)$ & $1(0.5)$ & & \\
\hline & East & $3(1.6)$ & $15(7.7)$ & $6(3.1)$ & & \\
\hline & West & $21(10.8)$ & $70(36.1)$ & $30(15.5)$ & & \\
\hline & Central & $3(1.6)$ & $7(3.6)$ & $2(1.0)$ & & \\
\hline \multirow{3}{*}{ Mother Education } & High School & $14(7.2)$ & $50(15.8)$ & $20(10.3)$ & \multirow{3}{*}{0.155} & \multirow{3}{*}{0.308} \\
\hline & Undergraduate & $11(5.8)$ & $26(13.4)$ & $14(7.2)$ & & \\
\hline & Postgraduate & $10(5.1)$ & $41(21.1)$ & $8(4.1)$ & & \\
\hline \multirow{3}{*}{ Father Education } & High School & $16(8.2)$ & $40(20.6)$ & $18(9.2)$ & \multirow{3}{*}{0.204} & \multirow{3}{*}{0.076} \\
\hline & Undergraduate & $5(2.6)$ & $28(14.4)$ & $15(7.7)$ & & \\
\hline & Postgraduate & $14(7.2)$ & $49(25.3)$ & $9(4.6)$ & & \\
\hline \multirow{2}{*}{ Hemoglobin } & Low & $25(12.8)$ & $84(43.3)$ & $32(16.5)$ & \multirow{2}{*}{0.013} & \multirow{2}{*}{0.986} \\
\hline & Normal & $5(2.6)$ & $17(8.8)$ & $7(3.6)$ & & \\
\hline \multirow{4}{*}{ BMI } & Underweight & $8(4.1)$ & $13(6.7)$ & $3(1.6)$ & \multirow{4}{*}{0.204} & \multirow{4}{*}{0.395} \\
\hline & Normal & $18(9.3)$ & $76(39.1)$ & $32(16.5)$ & & \\
\hline & Overweight & $6(3.1)$ & $13(6.7)$ & $4(2.1)$ & & \\
\hline & Obese & $3(1.5)$ & $14(7.2)$ & $3(1.5)$ & & \\
\hline
\end{tabular}

* Significant correlation at $<0.05$ level (2-taild). 
Table 2 below shows that the majority of the participants $(n=176,90.7 \%)$ never smoke either cigarettes or shisha. More than half of the participants $(n=101,52.1 \%)$ practice exercise less than three times a week. Moreover, two thirds of the participants $(n=125,64.4 \%)$ consumed less than three cups ofcaffeine per day. Around one half of the participants $(\mathrm{n}=111,57.2 \%)$ ate fruits and vegetables once a day, and a similar percentage $(n=103,54.2 \%)$ had breakfast some days. Furthermore, the majority of the participants $(n=192,99.0 \%)$ reported having stress, and half of the participants $(n=97$, $50 \%$ ) had stress each day of the academic year, particularly on exam days. Of the personal habits/lifestyle factors studied, only exercise had a significant effect on the severity of dysmenorrhea; less exercise led to an increase in the severity of dysmenorrhea $(\mathrm{p}=0.010)$. The researcher used further investigation tests to examine the relationship between exercising and the severity of dysmenorrhea by using Spearman correlation. There was a negative correlation between the two variables $(r=-0.163, n=194, p=0.010)$, with an increase in the intensity of dysmenorrhea among those who never exercise or who exercised less than three times per week. The severity of dysmenorrhea was decreased five times in the participants who had exercised more than three times per week compared to the participants who never exercised.

Table 2. Distribution of severity of dysmenorrhea with personal habits/life style.

\begin{tabular}{|c|c|c|c|c|c|c|c|}
\hline \multirow{2}{*}{ Personal Habit } & & & \multicolumn{3}{|c|}{ Severity of Dysmenorrhea } & \multirow{2}{*}{$\begin{array}{l}\text { Gamma } \\
\text { (spearman) }\end{array}$} & \multirow{2}{*}{ P - Value } \\
\hline & & & Mild n (\%) & Moderate n (\%) & Severe n (\%) & & \\
\hline \multirow{4}{*}{ Smoking } & Never & & $33(17.0)$ & $104(53.6)$ & $39(20.1)$ & \multirow{4}{*}{0.027} & \multirow{4}{*}{0.941} \\
\hline & Less than $5 /$ day & & $2(1.0)$ & $11(5.7)$ & $3(1.5)$ & & \\
\hline & $5-10 /$ day & & - & $1(0.5)$ & - & & \\
\hline & More than 10/day & & - & $1(0.5)$ & - & & \\
\hline \multirow{4}{*}{ Caffeine } & Never & & $8(4.1)$ & $15(7.7)$ & $6(3.1)$ & \multirow{4}{*}{0.047} & \multirow{4}{*}{0.848} \\
\hline & Less than 3 cups/day & & $19(9.8)$ & $79(40.7)$ & $27(13.9)$ & & \\
\hline & $3-5$ cups/day & & $5(2.6)$ & $17(8.8)$ & $7(3.6)$ & & \\
\hline & More than 5 cups/day & & $3(1.5)$ & $6(3.1)$ & $2(1.0)$ & & \\
\hline \multirow{4}{*}{$\begin{array}{l}\text { Fruits and } \\
\text { Vegetables }\end{array}$} & Rarely & & $1(0.5)$ & $15(7.7)$ & $4(2.1)$ & \multirow{4}{*}{-0.154} & \multirow{4}{*}{0.111} \\
\hline & 1 time/day & & $19(9.8)$ & $67(34.5)$ & $25(12.9)$ & & \\
\hline & 2 times/day & & $8(4.1)$ & $23(11.9)$ & $10(5.2)$ & & \\
\hline & 3 times/day and More & & $7(3.6)$ & $12(6.2)$ & $3(1.5)$ & & \\
\hline \multirow{3}{*}{$\begin{array}{l}\text { Drinking } \\
\text { Water }\end{array}$} & Less than $1.5 \mathrm{~L} /$ day & & $13(6.7)$ & $41(21.2)$ & $15(7.8)$ & \multirow{3}{*}{-0.018} & \multirow{3}{*}{0.815} \\
\hline & $1.5-2 \mathrm{~L} /$ day & & $16(8.3)$ & $63(32.6)$ & $22(11.4)$ & & \\
\hline & More than $2 \mathrm{~L} /$ day & & $6(3.1)$ & $12(6.2)$ & $42(2.6)$ & & \\
\hline \multirow{3}{*}{$\begin{array}{l}\text { Having } \\
\text { Breakfast }\end{array}$} & Never & & $1(0.5)$ & $7(3.7)$ & $4(2.1)$ & \multirow{3}{*}{-0.120} & \multirow{3}{*}{0.294} \\
\hline & Some days & & $18(9.5)$ & $61(32.1)$ & $24(12.6)$ & & \\
\hline & Every day & & $13(16.8)$ & $48(25.3)$ & $14(7.4)$ & & \\
\hline \multirow{12}{*}{ Present of stress } & \multirow{2}{*}{ Never } & No & $34(17.5)$ & $117(60.3)$ & $41(21.1)$ & \multirow{2}{*}{--} & \multirow{2}{*}{0.211} \\
\hline & & Yes & $1(0.5)$ & - & $1(0.5)$ & & \\
\hline & \multirow{2}{*}{ Exam days } & No & $20(10.3)$ & $62(32.0)$ & $27(13.9)$ & \multirow{2}{*}{-- } & \multirow{2}{*}{0.445} \\
\hline & & Yes & $15(7.7)$ & $55(28.4)$ & $15(7.7)$ & & \\
\hline & Activity days & No & $34(17.5)$ & $115(59.3)$ & $39(20.1)$ & & \\
\hline & Activity days & Yes & $1(0.5)$ & $2(1.0)$ & $3(1.5)$ & -- & 0.217 \\
\hline & Clinical davs & No & $29(14.9)$ & $100(51.5)$ & $36(18.6)$ & & 0022 \\
\hline & Cimlear days & Yes & $6(3.1)$ & $17(8.8)$ & $6(3.1)$ & -- & 0.922 \\
\hline & Assignment & No & $30(15.5)$ & $107(55.2)$ & $38(19.6)$ & & 0604 \\
\hline & Submission days & Yes & $5(2.6)$ & $10(5.2)$ & $4(2.1)$ & -- & 0.004 \\
\hline & All the vear & No & $21(10.8)$ & $59(30.4)$ & $17(8.8)$ & -- & 0231 \\
\hline & All tile yeal & Yes & $14(7.2)$ & $58(29.9)$ & $25(12.9)$ & - & 0.251 \\
\hline & Never & & $7(3.6)$ & $40(20.6)$ & $15(7.7)$ & & \\
\hline Fyercise & Less than 3 times/W & & $19(9.8)$ & $57(29.4)$ & $25(12.9)$ & & \\
\hline Exercise & 3 times/W & & $2(1.0)$ & $11(5.7)$ & - & & \\
\hline & More than 3 times/W & & $7(3.6)$ & $9(4.6)$ & $2(1.0)$ & $\begin{array}{l}-0.254 \\
(-0.163 *\end{array}$ & $0.010^{*}$ \\
\hline Odds Ratio Less & n 3 times & & 1.820 & 0.713 & 1.031 & & \\
\hline Odds Ratio $3 \mathrm{tim}$ & & & 1.43 & 3.022 & - & & \\
\hline Odds Ratio More & an 3 times & & 5.0 & 0.55 & 0.391 & & \\
\hline
\end{tabular}

* Significant correlation at $<0.05$ level (2-taild).

Table 3 presents the menstrual history of dysmenorrhea. More than two thirds of the participants $(n=137,71.4 \%)$ reported having menstruation in an age group of 12 to 16 years, which is within the natural range. Regarding the regularity of the menstrual cycle $(n=146,76.4 \%)$ of the participants reported a regular menstrual cycle, with intervals between 21 to 35 days for $(n=152,80.4 \%)$. The average period duration was three to seven days for $(n=174,90.6 \%)$ 
of participants. The number of pads used per day was four to eight pads, as reported by $(n=122,62.9 \%)$ of participants. A large number of participants $(n=168,87.0 \%)$ reported that they had moderate menstrual flow.

Regarding dysmenorrheal severity distribution with menstrual history, there was no significant association between menstrual history and the severity of dysmenorrhea, except for flow of menstruation level $(\mathrm{p}=0.011)$, according to the Chi-Square test. Using Spearman correlation, a positive correlation was found between heavy menstrual periods and severe dysmenorrhea $(\mathrm{r}=0.177, \mathrm{n}=194, \mathrm{p}=$ 0.013). Participants who had a heavy flow of menstruation were more likely to have severe dysmenorrhea than those who have a light or moderate flow of menstruation by 6.221 times.

Table 3. Distribution of severity of dysmenorrhea with menstrual history.

\begin{tabular}{|c|c|c|c|c|c|c|}
\hline \multirow{2}{*}{ Menstrual History } & & \multicolumn{3}{|c|}{ Severity of Dysmenorrhea } & \multirow{2}{*}{$\begin{array}{l}\text { Gamma } \\
\text { (Spearman) }\end{array}$} & \multirow{2}{*}{$\begin{array}{l}\text { P - Value (Fisher's } \\
\text { Exact Sig) }\end{array}$} \\
\hline & & Mild n (\%) & Moderate n (\%) & Severe n (\%) & & \\
\hline \multirow{3}{*}{ Age of Menarche } & Less than 12 & $11(5.7)$ & $29(15.1)$ & $10(5.2)$ & \multirow{3}{*}{0.516} & \multirow{3}{*}{0.951} \\
\hline & $12-16$ & $23(12.0)$ & $83(43.2)$ & $31(16.1)$ & & \\
\hline & More than 16 & $1(0.5)$ & $3(1.6)$ & $1(0.5)$ & & \\
\hline \multirow{2}{*}{ Menstrual Regularity } & Regular & $28(14.7)$ & $85(44.5)$ & $33(17.3)$ & \multirow{2}{*}{0.073} & \multirow{2}{*}{0.598} \\
\hline & Irregular & $7(3.7)$ & $30(15.7)$ & $8(4.2)$ & & \\
\hline \multirow{3}{*}{ Menstrual Interval } & Less than 21 days & $5(2.6)$ & $10(5.3)$ & $1(0.5)$ & \multirow{3}{*}{0.879} & \multirow{3}{*}{0.130} \\
\hline & $21-35$ days & $22(11.6)$ & $92(48.7)$ & $38(20.1)$ & & \\
\hline & More than 35 days & $6(3.2)$ & $12(6.3)$ & $3(1.6)$ & & \\
\hline \multirow{3}{*}{ Menstrual Duration of } & Less than 3 days & - & $1(0.5)$ & $1(0.5)$ & \multirow{3}{*}{0.646} & \multirow{3}{*}{0.100} \\
\hline & $3-7$ days & $31(16.1)$ & $109(56.8)$ & $34(17.7)$ & & \\
\hline & More than 7 days & $4(2.1)$ & $5(2.6)$ & $7(3.6)$ & & \\
\hline \multirow{2}{*}{$\begin{array}{l}\text { Number of Pads Per } \\
\text { Day }\end{array}$} & Less than 4 pads/day & $15(7.7)$ & $33(17.0)$ & $10(5.2)$ & \multirow[b]{2}{*}{0.119} & \multirow[b]{2}{*}{0.085} \\
\hline & $4-8$ pads/day & $16(8.2)$ & $79(40.7)$ & $27(13.9)$ & & \\
\hline \multirow{3}{*}{$\begin{array}{l}\text { Amount of Menstrual } \\
\text { Flow }\end{array}$} & Light & $4(2.1)$ & $3(1.6)$ & $1(0.5)$ & \multirow{5}{*}{$\begin{array}{l}0.029 \\
\left(0.177^{*}\right)\end{array}$} & \multirow{5}{*}{$\begin{array}{l}0.011^{*} \\
\left(0.013^{*}\right)\end{array}$} \\
\hline & Moderate & $28(14.5)$ & $107(55.4)$ & $33(17.1)$ & & \\
\hline & Heavy & $3(1.6)$ & $6(3.1)$ & $8(4.1)$ & & \\
\hline Odds Ratio Moderate & & 0.2 & 2.924 & 1.814 & & \\
\hline Odds Ratio Heavy & & 0.214 & 0.909 & 6.221 & & \\
\hline
\end{tabular}

* Significant correlation at $<0.05$ level (2-taild).

Table 4 shows that the majority of the participants $(n=191$, 98.5\%) have no children yet. It also found that around one third of the participants $(n=74,38.5 \%)$ reported not having a family history of dysmenorrhea, while one quarter $(n=53$,
$27.6 \%$ ) reported their mother and sister had dysmenorrhea. However, there was no statistical significance between the severity of dysmenorrhea and the obstetrical history using the Chi-Square test.

Table 4. Distribution of severity of dysmenorrhea with obstetrical history.

\begin{tabular}{|c|c|c|c|c|c|c|}
\hline \multirow{2}{*}{ Obstetrical History } & & \multicolumn{3}{|c|}{ Severity of Dysmenorrhea } & \multirow{2}{*}{$\mathbf{C ~ C ~}$} & \multirow{2}{*}{ P - Value } \\
\hline & & Mild n (\%) & Moderate n (\%) & Severe n (\%) & & \\
\hline \multirow{4}{*}{ Gravida } & None & $34(17.5)$ & $116(59.8)$ & $41(21.1)$ & \multirow{4}{*}{0.138} & \multirow{4}{*}{0.440} \\
\hline & $1-2$ & $1(0.5)$ & - & $1(0.5)$ & & \\
\hline & $3-4$ & - & $1(0.5)$ & - & & \\
\hline & More than 4 & - & - & - & & \\
\hline \multirow{4}{*}{ Para } & None & $33(17.0)$ & $116(59.8)$ & $42(21.6)$ & \multirow{4}{*}{0.159} & \multirow{4}{*}{0.081} \\
\hline & $1-2$ & $2(1.0)$ & $1(0.5)$ & - & & \\
\hline & $3-4$ & & & & & \\
\hline & More than 4 & - & - & - & & \\
\hline \multirow{4}{*}{ Abortion } & None & $35(18.0)$ & $116(59.8)$ & $42(21.6)$ & \multirow{4}{*}{0.058} & \multirow{4}{*}{0.718} \\
\hline & $1-2$ & - & $1(0.5)$ & - & & \\
\hline & $3-4$ & - & - & - & & \\
\hline & More than 4 & - & - & - & & \\
\hline \multirow{4}{*}{ Mode of Last Delivery } & None & $34(17.5)$ & $116(59.8)$ & $42(21.6)$ & \multirow{4}{*}{0.091} & \multirow{4}{*}{0.445} \\
\hline & Vaginal Delivery & $1(0.5)$ & $1(0.5)$ & - & & \\
\hline & Caesarian Section & - & - & - & & \\
\hline & Instrumental Delivery & - & - & - & & \\
\hline \multirow{4}{*}{$\begin{array}{l}\text { Family history of } \\
\text { dysmenorrhea }\end{array}$} & None & $13(6.8)$ & $47(24.5)$ & $14(7.3)$ & \multirow{4}{*}{0.132} & \multirow{4}{*}{0.132} \\
\hline & Mother & $2(1.0)$ & $18(9.4)$ & $5(2.6)$ & & \\
\hline & Sister & $10(5.2)$ & $21(10.9)$ & $4(2.1)$ & & \\
\hline & Mother and Sister & $9(4.7)$ & $29(15.1)$ & $15(7.8)$ & & \\
\hline
\end{tabular}




\begin{tabular}{|c|c|c|c|c|c|c|c|}
\hline \multirow{3}{*}{ Obstetrical History } & & & \multicolumn{3}{|c|}{ Severity of Dysmenorrhea } & \multirow{3}{*}{$\mathbf{C ~ C}$} & \multirow{2}{*}{ P - Value } \\
\hline & & & Mild n (\%) & Moderate n (\%) & Severe n (\%) & & \\
\hline & Relatives & & - & $2(1.0)$ & $3(1.6)$ & & \multirow{3}{*}{0.560} \\
\hline \multirow{7}{*}{ Contraceptive used } & \multirow{2}{*}{ None } & No & $1(0.5)$ & $2(1.0)$ & $2(1.0)$ & \multirow{2}{*}{--} & \\
\hline & & Yes & $34(17.5)$ & $115(59.3)$ & $40(20.6)$ & & \\
\hline & \multirow[t]{2}{*}{ Mini Pill } & No & $42(21.6)$ & $116(59.8)$ & $35(18.0)$ & \multirow[t]{2}{*}{--} & \multirow[t]{2}{*}{0.718} \\
\hline & & Yes & - & $1(0.5)$ & - & & \\
\hline & Companied Oral & No & $41(21.1)$ & $115(59.2)$ & $35(18.0)$ & \multirow[b]{2}{*}{--} & \multirow{2}{*}{0.683} \\
\hline & Contraceptive & Yes & - & $2(1.0)$ & $1(0.5)$ & & \\
\hline & Other ( Vaginal Ring) & $\begin{array}{l}\text { No } \\
\text { Yes }\end{array}$ & $\begin{array}{l}41(21.1) \\
1(0.5)\end{array}$ & $117(60.3)$ & $\begin{array}{l}34(17.5) \\
1(0.5)\end{array}$ & -- & 0.211 \\
\hline \multirow{5}{*}{ Gynecological Disorder } & None & $\begin{array}{l}\text { No } \\
\text { Yes }\end{array}$ & $\begin{array}{l}4(2.1) \\
31(16.0)\end{array}$ & $\begin{array}{l}12(6.18) \\
105(54.1)\end{array}$ & $\begin{array}{l}4(2.1) \\
38(19.6)\end{array}$ & -- & 0.963 \\
\hline & Ovarian Cyst & $\begin{array}{l}\text { No } \\
\text { Yes }\end{array}$ & $\begin{array}{l}41(21.1) \\
4(2.1)\end{array}$ & $\begin{array}{l}114(59.0) \\
3(1.6)\end{array}$ & $\begin{array}{l}31(16.0) \\
1(0.5)\end{array}$ & -- & 0.056 \\
\hline & \multirow{2}{*}{$\begin{array}{l}\text { Other (Polycystic } \\
\text { ovary) }\end{array}$} & No & $42(21.6)$ & $117(60.3)$ & $34(17.5)$ & \multirow{2}{*}{--} & \multirow{2}{*}{0.102} \\
\hline & & Yes & $1(0.5)$ & - & - & & \\
\hline & I do not know & $\begin{array}{l}\text { No } \\
\text { Yes }\end{array}$ & $\begin{array}{l}39(20.1) \\
-\end{array}$ & $\begin{array}{l}109(56.2) \\
8(4.1)\end{array}$ & $\begin{array}{l}35(18.0) \\
3(1.5)\end{array}$ & -- & 0.276 \\
\hline
\end{tabular}

* Significant correlation at $<0.05$ level (2-taild).

Table 5 illustrates that the most common outcome of dysmenorrhea on participants' physical and psychological wellbeing were a depressed mood $(n=157,80.9 \%)$, sleep disturbance $(\mathrm{n}=127,65.5 \%)$, decreased social activities $(\mathrm{n}=$ $126,64.9 \%)$, and conflict with others $(n=105,54.1 \%)$. Only $(n=6,3.1 \%)$ of the participants stated different impacts, such as a bad mood and crying, less appetite, losing focus, stress, and low performance. There is a significant association between the severity of dysmenorrhea and a feeling of inferiority, sleeping disturbance, depressed mood, decreased social activities, and conflict with others according to the Chi-Square test.

Table 5. Distribution of severity of dysmenorrhea with physical and psychological wellbeing.

\begin{tabular}{|c|c|c|c|c|c|}
\hline \multirow[b]{2}{*}{ The impacts } & & \multicolumn{3}{|c|}{ Severity of Dysmenorrhea } & \multirow[b]{2}{*}{$P$ - Value } \\
\hline & & $\begin{array}{l}\text { Mild } \\
\text { n (\%) }\end{array}$ & $\begin{array}{l}\text { Moderate } \\
\text { n (\%) }\end{array}$ & $\begin{array}{l}\text { Severe } \\
\text { n(\%) }\end{array}$ & \\
\hline \multirow{2}{*}{ Increase weight } & No & $26(13.4)$ & $89(45.9)$ & $32(16.5)$ & \multirow{2}{*}{1.000} \\
\hline & Yes & $9(4.6)$ & $28(14.4)$ & $10(5.2)$ & \\
\hline \multirow{2}{*}{ Decrease weight } & No & $30(15.5)$ & $108(55.7)$ & $34(17.5)$ & \multirow{2}{*}{0.117} \\
\hline & Yes & $5(2.6)$ & $9(4.6)$ & $8(4.1)$ & \\
\hline \multirow{2}{*}{ Feeling inferiority } & No & $28(14.4)$ & $100(51.5)$ & $26(13.4)$ & \multirow{2}{*}{$0.005^{*}$} \\
\hline & Yes & $7(3.6)$ & $17(8.8)$ & $16(8.2)$ & \\
\hline \multirow{2}{*}{ Sleep disturbance } & No & $20(10.3)$ & $39(20.1)$ & $8(4.1)$ & \multirow{2}{*}{$0.002 *$} \\
\hline & Yes & $15(7.7)$ & $78(40.2)$ & $34(17.5)$ & \\
\hline \multirow{2}{*}{ Depressed mood } & No & $12(6.2)$ & $24(12.4)$ & $1(0.5)$ & \multirow{2}{*}{$0.001 *$} \\
\hline & Yes & $23(11.9)$ & $93(47.9)$ & $41(21.1)$ & \\
\hline \multirow{2}{*}{ Decreased social activity } & No & $17(8.8)$ & $44(22.7)$ & $7(3.6)$ & \multirow{2}{*}{$0.009 *$} \\
\hline & Yes & $18(9.3)$ & $73(37.6)$ & $35(18.0)$ & \\
\hline Conflicts with other & Yes & $13(6.7)$ & $64(33.0)$ & $28(14.4)$ & $0.034^{*}$ \\
\hline \multirow{2}{*}{ Other } & No & $34(17.5)$ & $113(58.2)$ & $41(21.1)$ & \multirow{2}{*}{1.000} \\
\hline & Yes & $1(0.5)$ & $4(2.1)$ & $1(0.5)$ & \\
\hline
\end{tabular}

* Significant correlation at $<0.05$ level (2-taild).

\section{Discussion}

The factors associated with dysmenorrhea had some overlap with the results found in the literature. In the present study, only exercise was significantly associated with the reduction of the severity of dysmenorrhea; those who exercised three times per week were less likely to develop moderate or severe dysmenorrhea than those who did not. Exercise reduces menstrual pain by helping improve blood flow to the pelvic area, as well as stimulating the release of endorphins, which, in turn, release natural pain killers and act as non-specific analgesics [7]. The positive effect of exercise is supported by an Iranian study, conducted by Noorbakhsh et al. among 50 students with moderate to severe primary dysmenorrhea; that study indicated that those who participated in physical activity programs were less likely to have menstrual pain [12]. Conversely, studies by Ameade et al. and Ibrahim et al. showed no association between exercise and the severity of dysmenorrhea [5,9]. From these studies, it can be concluded that exercise must be enhanced among 
dysmenorrheal women to reduce menstrual pain.

The present study revealed that only heavy menstruation was associated with an increase in the pain intensity of dysmenorrhea. Similarly, studies conducted in Saudi Arabia and Egypt found a positive correlation between heavy and painful menses $[9,13]$. However, a study conducted by Karanth and Liya showed no relationship between the severity of dysmenorrhea and menstrual flow [7]. A comprehensive review by Ju et al. was unable to draw a firm conclusion on the association of heavy menstrual flow and increased intensity of dysmenorrhea, due to the limited number of studies reporting these effects [4].

The present study found no significant association between the severity of dysmenorrhea and smoking or caffeine consumption. This agrees with results by Memnun et al., which confirmed that participants' smoking status and coffee and tea consumption levels did not affect their dysmenorrhea status [14]. The fact that most of nursing students in the current study were non-smokers may be attributed to a societal awareness about the adverse effects of smoking.

In addition, the present study did not find any significant association between the severity of dysmenorrhea and eating fruits and vegetables; cross-sectional studies by Gangwar et al. and Najafi et al. reported similar findings]. [15, 16].

In the present study, more than half of the nursing students did not eat breakfast on some days. However, no significant relationship was found between eating breakfast and the severity of dysmenorrhea. This finding corresponds with Eittah's study of Egyptian nursing students at Menoufiya University; participants who skipped breakfast had a significantly higher degree of dysmenorrheal symptoms than those who ate breakfast [17]. Skipping breakfast has been an increasing trend over the last decade and is a growing health problem [18]. While the mechanisms underlying the adverse effects of skipping a meal are unclear, studies identifying dietary factors that affect dysmenorrheal pain are warranted.

The present study did not find a significant relationship between the severity of dysmenorrhea and stress, despite the fact that the majority of nursing students reported stress during the academic year. Studies by Ibrahim et al. and Abu Helwa et al. found that stress was one of the main predictors of dysmenorrhea among medical students $[8,9]$. The prevailing reason for the stress among the nursing students in the present study could be due to the busy, demanding schedule of the nursing program and its curriculum. Lee et al. concluded that, physiologically, stress leads to the impairment of follicular development, which could potentially reduce progesterone synthesis and release. Reduced progesterone may cause the increased production of prostaglandin, which leads to increased uterine muscle contraction, resulting in dysmenorrhea [19].

Although a high percentage of low haemoglobin was identified among dysmenorrheal nursing students in the present study, a statistically significant association between the severity of dysmenorrhea and low haemoglobin levels was not found. This is consistent with a study by Karanth and Liya, which reported that anaemia did not have a significant association with dysmenorrhea [7]. Low haemoglobin could be due to a heavy menstrual flow and skipping breakfast. It is recommended to conduct research on the relation between low haemoglobin and dysmenorrhea on a large sample size.

In the present study, the association between the severity of dysmenorrhea and BMI was not statistically significant; this could be because the majority of studied nursing students had normal BMI levels. This is consistent with a crosssectional study that aimed to evaluate the prevalence of dysmenorrhea and its effects on daily routine activities and quality of life among 100 Indian nursing students; that study reported that there was not a significant relationship between dysmenorrhea and BMI [20]. Meanwhile, a longitudinal study found a high association between dysmenorrhea and both obesity and being underweight [21].

Additionally, the present study did not reveal a significant association between the severity of dysmenorrhea and menstrual regularity, duration or menstrual intervals. Likewise, a Turkish study by Potur et al. of 1515 female university students did not find a significant relationship between the severity of dysmenorrhea and menstrual duration, but it did find a significant association with menstrual regularity [11]. Additional studies are needed to explore normal menstrual patterns and their association with dysmenorrhea.

Although the literature has suggested that age of menarche is an important factor of dysmenorrhea $[1,22,10]$, the present study did not find a statistical significance between dysmenorrheal severity and age of menarche. This result is consistent with Ismaile et al., who studied 100 Saudi nursing students [23]. A similar result was found in a study by AlJefout et al. which was conducted among 272 Jordanian female medical students [24]. One of the reasons that the present study did not find a significant association between the age of menarche and dysmenorrhea could be the small number of nursing students who experienced menarche when younger than 12 or older than 16 .

Furthermore, the present study did not find a statistical significance between dysmenorrhea and a family history of dysmenorrhea. This finding is in line with Al-Jefout et al.'s study [24], but differs from another study, which found that a family history of dysmenorrhea was significantly associated with dysmenorrhea $[6,10,25]$. However, more than one quarter of nursing students in the present study reported a family history of dysmenorrhea. This finding could be related to conditioned behaviours for coping with pain, which were learned from participants' mothers and/or sisters. Alternatively, it could simply be due to similar living patterns and lifestyles in the families.

Significantly, the present study found that dysmenorrhea led to feelings of inferiority, sleep disturbances, depressed mood, decreased social activity and conflicts with others. Similarly, a cross-sectional study conducted among 435 Saudi medical female students at KAU found that depressed mood and anger were the most common complaints associated with dysmenorrhea [9]. This confirms the fact that dysmenorrhea is a constant illness among women, which can negatively affect their daily physical, social and 
psychological wellbeing [26].

\section{Conclusion}

Dysmenorrhea is one of the most common female health complaints, and it can negatively affect quality of life. Among the various factors investigated, a heavy menstrual flow was the strongest factor of the intensity of dysmenorrhea. Practicing exercise at least three times per week helped reduce the severity of dysmenorrhea in the study participants. Unfortunately, the type of exercise performed by participants was not explored in the present study; it is recommended that this parameter be examined in future studies. Researchers and healthcare providers should pay attention to the associated factors to reduce the intensity of dysmenorrhea and its adverse effects in young female students.

\section{References}

[1] Shaji JC. H. (2014) .Severity of primary dysmenorrhea and menstrual distress among university students in kingdom of Saudi Arabia. International Journal of Health Sciences and Research. ISSN: 2249-9571.

[2] Allen LM, and Lam AC. (2012). Premenstrual syndrome and dysmenorrhea in adolescents. Adolesc Med State Art Rev. 2012;23:139-163.

[3] Iacovides, S., Avidon, I., and Baker, F., (2015). What we know about primary dysmenorrhea today: a critical review. Human Reproduction Update, 21(6), $762-778$. doi:10.1093/humupd/dmv039.

[4] Hong Ju,Jones M, and Mishra G., (2014). The prevalence and risk factors of dysmenorrhea. Epidemiological Reviews, 36, 104-113. doi: 10.1093/epirev/mxt009.

[5] Ameade, E. P. K., Amalba, A., and Mohammed, B. S. (2018). Prevalence of dysmenorrhea among University students in Northern Ghana; its impact and management strategies. BMC Women's Health, 18(1). https://doi.org/10.1186/s12905-0180532-1.

[6] Hailemeskel, S. Assefa, N., and Demissie, A., (2016). Primary dysmenorrhea magnitude, associated risk factors, and its effect on academic performance: evidence from female university students in Ethiopia. International Journal of Women's Health, Volume 8, 489-496. doi: 10.2147/ijwh.s112768

[7] Karanth S, and Liya SR. (2018). Prevalence and risk factors for dysmenorrhea among nursing student and its impact on their quality of life. Int $J$ ReprodContraceptObstet Gynecol,7:2661-7.

[8] Abu Helwa, H. A., Mitaeb, A. A., Al-Hamshri, S., and Sweileh, W. M. (2018). Prevalence of dysmenorrhea and predictors of its pain intensity among Palestinian female university students. BMC Women's Health, 18(1). https://doi.org/10.1186/s12905-018-0516-1.

[9] Ibrahim, N. K., Alghamdi, M. S., Al-Shaibani, A. N., Alamri, F. A., Alharbi, H. A., Al-Jadani, A. K., and Alfaidi, R. A. (2015). Dysmenorrhea among female medical students in king abdulaziz university: Prevalence, predictors and outcome.
Pakistan Journal of Medical Sciences, 31(6), 1312-1317. https://doi.org/10.12669/pjms.316.8752.

[10] Tatyana A., Taiwo O., Chinedu N., and Ufuoma A. (2017). Dysmenorrhea and impact on Quality of Life. Journal of Current Medical Research And Opinion, 1(3). doi: 10.15520/jcmro.v1i3.16.

[11] Potur, D. C., Bilgin, N. C., and Komurcu, N. (2014). Prevalence of dysmenorrhea in university students in turkey: Effect on daily activities and evaluation of different pain management methods. Pain Management Nursing, 15(4), 768-777. https://doi.org/10.1016/j.pmn.2013.07.012.

[12] NoorbakhshMahvash, AlijaniEidy, Kohandel Mehdi, MehdizadehToorzani Zahra, Mirfaizi Mani and HojatShahla. (2012). The Effect of Physical Activity on Primary Dysmenorrhea of Female University Students. World Applied Sciences Journal 17 (10): 1246-1252, ISSN 1818-4952.

[13] Kamel, D. M., Tantawy, S. A., and Abdelsamea, G. A. (2017). Experience of dysmenorrhea among a group of physical therapy students from Cairo University: An exploratory study. Journal of Pain Research, 10, 1079-1085. https://doi.org/10.2147/JPR.S132544.

[14] MemmunSeven, GültenGüvenç, AygülAkyüz, \&FatmaEski, (2014). Evaluating Dysmenor-rhea in a Sample of Turkish Nursing Students. Pain Management Nursing, Volume 15, Is$\begin{array}{lllll}\text { sue } & 3, & 664 & - & 671,\end{array}$ https://doi.org/10.1016/j.pmn.2013.07.006.

[15] Gangwar, V., Kumar, D., Gangwar, R., Arya, M., and Banoo, H. (2014). Prevalence of Primary Dysmenorrhea among the Undergraduate Medical Students and its Impact on their Performance in Study. International Journal of Physiology, 2(1), 14. doi: 10.5958/j.2320-608x.2.1.004.

[16] Najafi Nastaran, Khalkhali Hamidreza, Fatemeh Moghaddam Tabrizi, and Rasoul Zarrin. (2018) Major dietary patterns in relation to menstrual pain: a nested case control study. $B M C$ Womens Health. 2018; 18: 69. doi: [10.1186/s12905-0180558-4].

[17] Eittah, H. F. A. (2014). Effect of breakfast skipping on young females' menstruation. Health Science Journal, 8(4), 469-484.

[18] Ministry of Health, Labour and Welfare, Japan (2014). The National Health and Nutrition Survey in Japan, 2012. Ministry of Health, Labour and Welfare, Tokyo, Japan (in Japanese).

[19] Lee LC, Tu CH, Chen LF, Shen HD, Chao HT, and Lin MW, et al. (2014). Association of brain-derived neurotropic factor gene Val66Met polymorphism with primary dysmenorrhea. PLoS One. 2014 Nov 10;9(11):e112766 doi: 10.1371/journal.pone.0112766.

[20] Ghanghoriya V, Patel K, and Markam R. (2018). Prevalence of dysmenorrhoea and its effect on quality of life among nursing students. Int $J$ ReprodContraceptObstet Gynecol;7: 2129-35.

[21] Hong Ju, Jones M, \& Mishra GD. (2015). A U-shaped relationship between Body Mass Index and dysmenorrhea: A Longitudinal study. PLoS ONE 2015;10:e134187.

[22] Pejčić, A., and Janković S., (2016). Risk factors for dysmenorrhea among young adult female university students. AnnaliDell'IstitutoSuperiore Di Sanita, 52(1), 98-103. https://doi.org/10.4415/ANN_16_01_16. 
[23] Ismaile, S., Al-Enezi, S., Otaif, W., Al-Mahadi, A., Bingorban, N., and Barayaan, N. (2016). Prevalence of Menstrual Pain among Saudi Nursing Students and Its Effect on Sickness Absenteeism. Health, 08(03), 198-205. https://doi.org/10.4236/health.2016.83023.

[24] Al-Jefout, M., Seham, A.-F., Jameel, H., Randa, A.-Q., Ola, A.-M., Oday, A.-M., and Luscombe, G. (2015). Dysmenorrhea: Prevalence and Impact on Quality of Life among Young Adult Jordanian Females. Journal of Pediatric and Adolescent Gynecology, 28(3), 173-85. https://doi.org/10.1016/j.jpag.2014.07.005.
[25] Gebeyehu, M. B., Mekuria, A. B., Tefera, Y. G., Andarge, D. A., Debay, Y. B., Bejiga, G. S., and Gebresillassie, B. M. (2017). Prevalence, Impact, and Management Practice of Dysmenorrhea among University of Gondar Students, Northwestern Ethiopia: A Cross-Sectional Study. International Journal of Reproductive Medicine, 2017, 1-8. https://doi.org/10.1155/2017/3208276.

[26] Shewte M. and Sirpurkar M. (2016). Dysmenorrhoea and quality of life among medical and nursing students: a cross sectional study. National Journal of Community Medicine 7 (6) : 474- 9 . 